\title{
Influence of porous silicon formation on the performance of multi-crystalline silicon solar cells
}

\author{
M SAAD* and M NADDAF \\ Atomic Energy Commission of Syria, P.O. Box 6091, Damascus, Syria
}

MS received 29 May 2014; revised 4 September 2014

\begin{abstract}
The effect of formation of porous silicon on the performance of multi-crystalline silicon (mc-Si) solar cells is presented. Surface treatment of mc-Si solar cells was performed by electrochemical etching in HF-based solution. The effect of etching is viewed through scanning electron microscope (SEM) photographs that indicated the formation of a porous layer on the surface. Total reflection spectroscopy measurements on solar cells revealed reduced reflection after etching. In order to demonstrate the effect of this porous layer on the solar cell performance, illumination-dependent $\boldsymbol{j}-\boldsymbol{V}$ characteristics and spectral response measurements were performed and analysed before and after etching. At all illumination intensities, short-circuit current density and open-circuit voltage values for the etched solar cell were higher than those before etching, whereas fill factor values were lower for the etched cell at high illumination intensities. An interpretation of these findings is presented.
\end{abstract}

Keywords. Porous silicon; solar cells; two-diode model; $j-V$ characteristics.

\section{Introduction}

Porous silicon has a potential for various applications in sensing and photonic devices. ${ }^{1-5}$ The most widely applied features of porous silicon for solar cell applications include antireflection coating (ARC), surface texturing and surface passivation. ${ }^{6-9}$ Porous silicon thin films have relatively high optical absorption coefficient. Therefore, they can be used to reduce the reflection and improve the light absorption in the useful photovoltaic spectral range in multi-crystalline silicon (mc-Si) solar cells. The effectiveness of the porous layer as the antireflecting coating of the solar cell is confirmed. ${ }^{10-12}$ The porous silicon etch process has been implemented after junction formation and metallization. This approach can lead to selective emitter formation, proper surface reflectance and good electrical contact. ${ }^{13}$

In this paper the influence of porous silicon formation on the performance of mc-Si solar cells is presented. The porous silicon layer was formed selectively in the regions not covered by the grid, maintaining the front contact grid unchanged.

\section{Experimental}

The analysed cell was a $1.2 \mathrm{~cm}^{2}$ partition of a cell denoted Q6-1380 (not encapsulated), which was thankfully provided by Q-Cells AG, Germany. Table 1 summarizes the cell properties taken from its datasheet.

The surface of the cell (top side) was anodized in an electrolytic solution of $44 \% \mathrm{HF}$ and $99.99 \%$ ethanol in a

\footnotetext{
*Author for correspondence (pscientific1 @ aec.org.sy)
}

proportion of $1: 1$. The electrochemical etching cell was designed in single tank geometry. ${ }^{14}$ It consisted of two Teflon cylindrical sections, with a cavity in the upper section for electrolyte injection. A platinum electrode immersed in the electrolyte solution and an aluminium plate served as two electrodes of the cell. A pulsed power supply with output voltage operating in a constant voltage mode similar to one described elsewhere, ${ }^{15}$ was used for the etching process. Under darkness, the 120 s etching process was carried out by applying a pulsed current between the two electrodes; at peak current density of $10 \mathrm{~mA} \mathrm{~cm}^{-2}$ with pulse duration of $10 \mathrm{~ms}$. After etching, the cell was rinsed with de-ionized water, dried in $\mathrm{N}_{2}$ stream.

Current-voltage characteristics were measured at room temperature before and after etching and investigated under several low illumination levels. Measurements were performed using a Keithley 238 Source Measure Unit (SMU) through a four-point connection. Halogen lamps were used for illumination, whereas a silicon calibration cell was used to set the illumination level. The illumination level was varied between 0 (dark) and $32 \mathrm{~mW} \mathrm{~cm}^{-2}$. In order to analyse cell photocurrent spectral response and reflectivity measurements were performed using an Optosolar spectrophotometer system SR 300 equipped with an integrating sphere in the wavelength range of 400-1100 $\mathrm{nm}$.

\section{Results and discussion}

Figure 1 shows scanning electron microscope (SEM) photographs for the cell; (a) before and (b) after etching. The clear change in the surface topography after etching process represents an evidence of porous silicon formation. 
Table 1. Data of the cell Q6-1380 provided by Q-Cells AG, Germany. The studied cell was a $1.2 \mathrm{~cm}^{2}$ partition of this cell.

\begin{tabular}{ll}
\hline Product & Multi-crystalline silicon solar cell \\
Format & $150 \mathrm{~mm} \times 150 \mathrm{~mm} \pm 1 \mathrm{~mm}$ \\
Thickness & $300 \pm 40 \mu \mathrm{m}$ \\
Front $(-)$ & $2 \mathrm{~mm}$ bus bars (silver), blue anti-reflection coating (silicon nitride) \\
Back $(+)$ & $5 \mathrm{~mm}$ wide soldering pads (silver/aluminium), back surface field (aluminium) \\
\hline
\end{tabular}
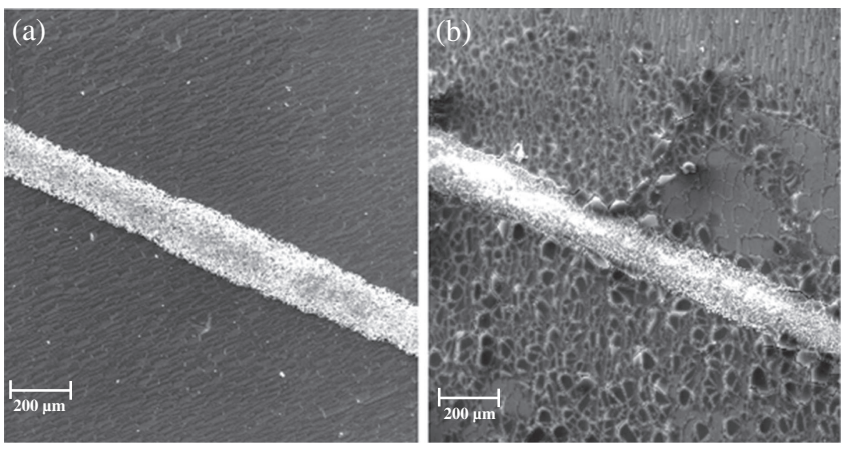

Figure 1. Surface SEM photographs for the cell before and after etching. Etching was performed for $2 \mathrm{~min}$.

The white line represents the bus bar that forms the front contact. Although the front contact is slightly damaged due to etching, cell characteristics could be measured as it will be demonstrated below.

Figure 2 shows the $j-V$ curves measured at room temperature for various illumination level values between $I_{\text {ill }}=0$ (dark) and $I_{\mathrm{ill}}=32 \mathrm{~mW} \mathrm{~cm}{ }^{-2}$ for the mc-Si cell before and after etching. From this figure the photovoltaic parameters (short-circuit current density, open-circuit voltage, fill factor and solar cell conversion efficiency) were obtained and are presented in figure 3 depending on illumination intensity.

Figure 3 clearly shows that both short-circuit current density and open-circuit voltage increase with the increase in illumination intensity, and that their values for the etched cell are higher than the corresponding values before cell etching. In particular, the short-circuit current density increases from $j_{\mathrm{sc}}=0.136 \mathrm{~mA} \mathrm{~cm}^{-2}$ (at an illumination intensity of $I_{\mathrm{ill}}=$ $5.55 \mathrm{~mW} \mathrm{~cm}^{-2}$ ) to $j_{\mathrm{sc}}=10 \mathrm{~mA} \mathrm{~cm}{ }^{-2}$ (at an illumination intensity of $I_{\text {ill }}=32 \mathrm{~mW} \mathrm{~cm}^{-2}$ ) before etching, while after etching it increases from $j_{\mathrm{sc}}=0.1$ to $j_{\mathrm{sc}}=12.7 \mathrm{~mA} \mathrm{~cm}^{-2}$ at the corresponding illumination intensity values. Opencircuit voltage also increases from $V_{\mathrm{oc}}=0.286 \mathrm{~V}$ (at an illumination intensity of $I_{\text {ill }}=5.55 \mathrm{~mW} \mathrm{~cm}^{-2}$ ) to $V_{\text {oc }}=$ $0.542 \mathrm{~V}$ (at an illumination intensity of $I_{\mathrm{ill}}=32 \mathrm{~mW} \mathrm{~cm}^{-2}$ ) before etching, while after etching it increases from $V_{\mathrm{oc}}=$ $0.256 \mathrm{~V}$ to $V_{\mathrm{oc}}=0.547 \mathrm{~V}$ at the corresponding illumination intensity values. While fill factor values of the cell before etching increase with the increase in illumination intensity (from $\mathrm{ff}=51 \%$ at an illumination intensity of $I_{\text {ill }}=5.55 \mathrm{~mW}$ $\mathrm{cm}^{-2}$ to $\mathrm{ff}=69 \%$ at an illumination intensity of $I_{\text {ill }}=32$ $\mathrm{mW} \mathrm{cm}{ }^{-2}$ ), those values of the etched cell increase for low illumination intensity values up to a certain value ( $\mathrm{ff}=62 \%$
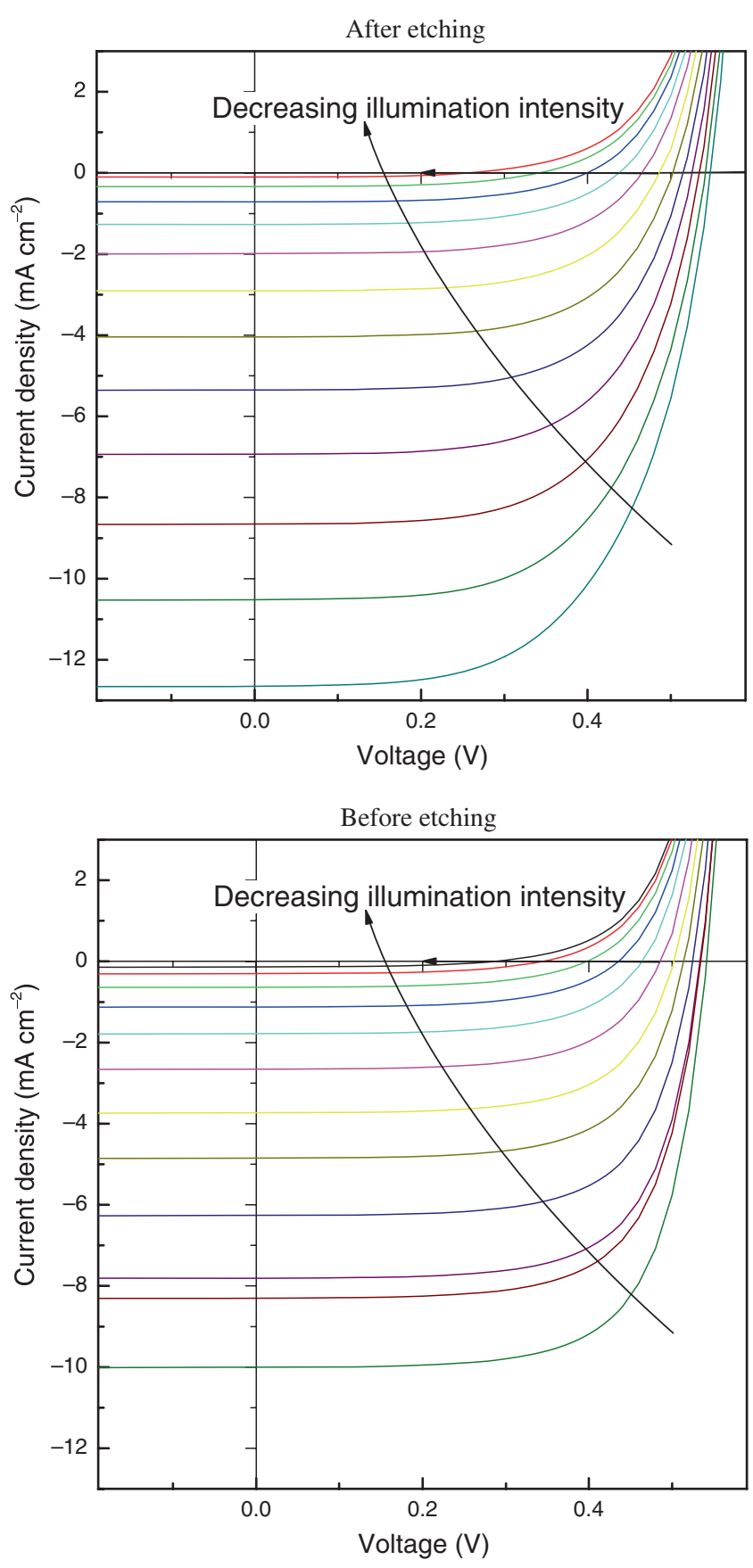

Figure 2. Dependence of the $j-V$ characteristics of the mc-Si cell before and after etching on illumination intensity. The illumination was performed using a halogen lamp, and the illumination intensity was varied between $I_{\text {ill }}=0$ (dark) and $I_{\text {ill }}=32 \mathrm{~mW} \mathrm{~cm}^{-2}$ using neutral density filters. 

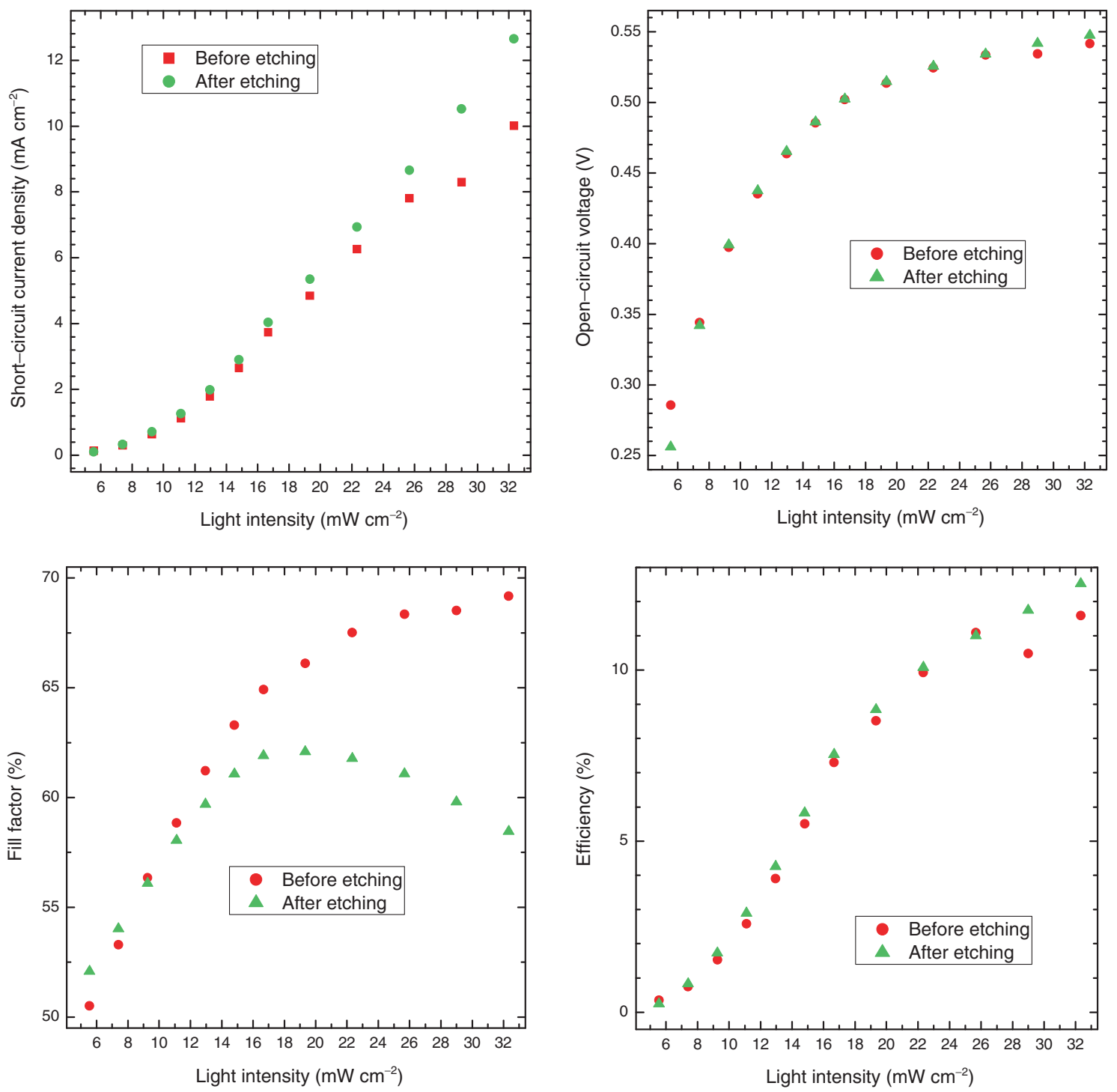

Figure 3. Dependence of the photovoltaic parameters (short-circuit current density, open-circuit voltage, fill factor and solar cell conversion efficiency) on illumination intensity.

at an illumination intensity of $I_{\text {ill }}=19.33 \mathrm{~mW} \mathrm{~cm}^{-2}$ ), and then start to decrease with the increase in illumination intensity, and it reaches the value of $\mathrm{ff}=58 \%$ at an illumination intensity of $I_{\text {ill }}=32 \mathrm{~mW} \mathrm{~cm}{ }^{-2}$. Altogether the solar cell conversion efficiency values remain higher for the etched cell than for the cell before etching for all illumination intensity values (for instance at an illumination intensity of $I_{\text {ill }}=$ $32 \mathrm{~mW} \mathrm{~cm}^{-2}$ the solar cell conversion efficiency value before etching is $\eta=11.6 \%$, while the corresponding efficiency value after etching is $\eta=12.5 \%$ ).

In order to explain this behaviour spectral response and reflectivity measurements were performed before and after etching. Figure 4a shows spectral response of both cells in the wavelength range between 400 and $1100 \mathrm{~nm}$. It clearly shows that the spectral response of the etched cell is higher than that for the cell before etching in the entire wavelength range. This explains the higher short-circuit current density-and therefore also higher open-circuit voltage values-of the etched cell than those of the cell before etching. This statement is confirmed through reflection measurements of both cells, which are presented in figure $4 \mathrm{~b}$. This figure demonstrates that cell etching leads to a decrease in the reflection. In the literature porous silicon is proposed to act as an antireflection layer. ${ }^{10-12}$

In order to quantify the short-circuit current increase after etching the external quantum efficiency was calculated from the spectral response measurements using the equation

$$
\operatorname{SR}(\lambda)=\frac{\lambda Q_{\mathrm{ext}}(\lambda)}{h c},
$$

where the quantities $\lambda, \operatorname{SR}(\lambda), Q_{\text {ext }}(\lambda), h, c$ are respectively, the wavelength, the spectral response, the external quantum efficiency, the Planck constant and the speed of light in a vacuum.

The short-circuit current was then calculated from the spectral quantum efficiency folded with the halogen lamp 
(a)

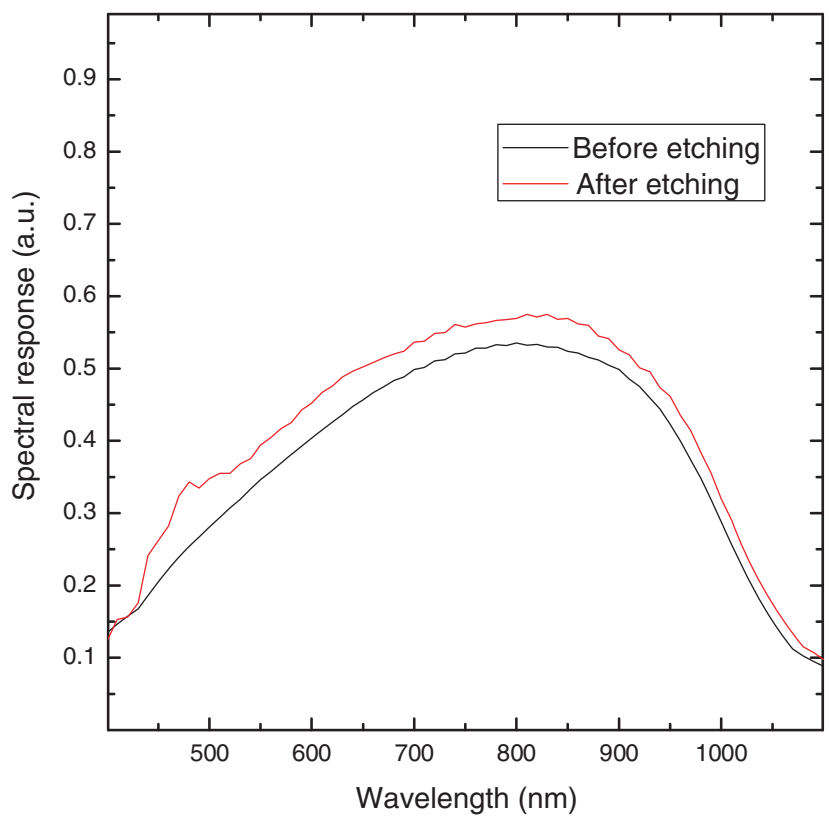

(b)

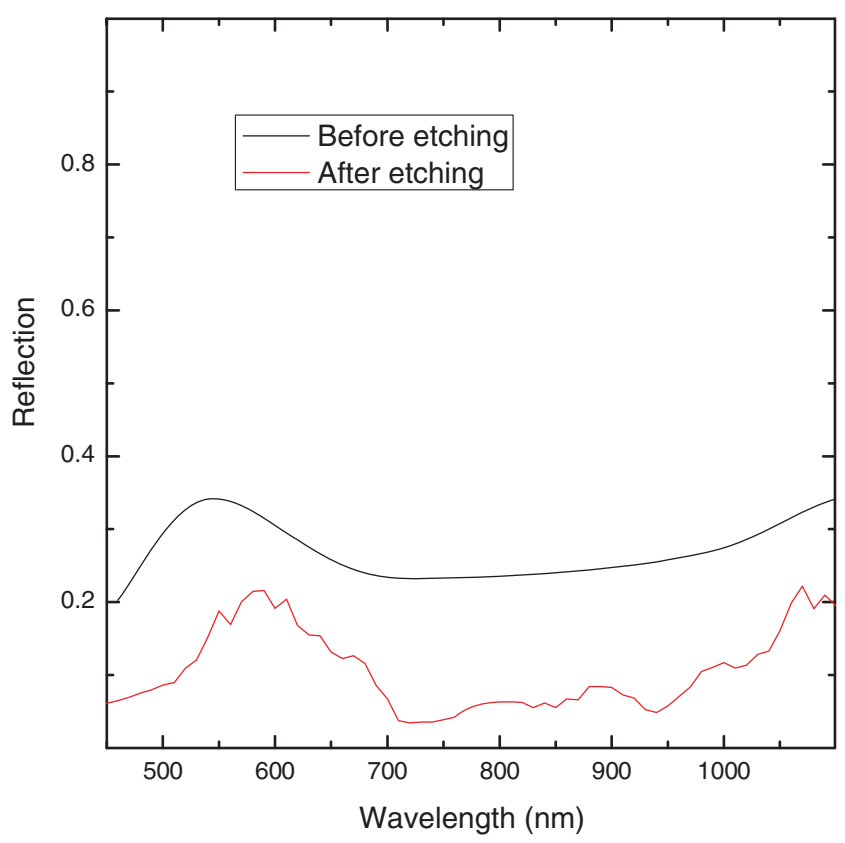

Figure 4. (a) Spectral response and (b) reflection of the studied cell before and after etching.

spectrum and integrated over the relevant wavelength range between 400 and $1100 \mathrm{~nm}$ using the equation

$$
j_{\mathrm{sc}}=q \int_{400}^{1100} Q_{\text {ext }}(\lambda) \Phi(\lambda) \mathrm{d} \lambda,
$$

where $\Phi(\lambda)$ is the illumination spectrum.

The intensity of the illumination spectrum was set so that the integration reveals a short-circuit current of $j_{\mathrm{sc}}=10 \mathrm{~mA} \mathrm{~cm}^{-2}$ for the solar cell before etching. Calculation of the short- circuit current density for the solar cell after etching using the same procedure with the same illumination intensity (which was set for the cell before etching) revealed a shortcircuit current density of $j_{\mathrm{sc}}=12.66 \mathrm{~mA} \mathrm{~cm}^{-2}$, with a good agreement of the experimental value of $j_{\mathrm{sc}}=12.7 \mathrm{~mA} \mathrm{~cm}^{-2}$.

The interpretation of the fill factor behaviour is more complicated than that of both short-circuit current and opencircuit voltage. For this interpretation current-voltage characteristics at each illumination intensity should be analysed.

In a recent work, a modified two-diode equivalent circuit accounting for an additional ohmic series resistance in the vicinity of grain boundaries was proposed in order to accurately describe current-voltage characteristics of mc-Si solar cells, especially under low illumination levels. ${ }^{16}$ The essential features of this model are presented below.

The model is based on the assumptions that the cell consists of two different regions with different current transport mechanisms: the crystalline region and the grain boundary region, accounted by the two parallel diodes $\mathrm{D}_{1}$ and $\mathrm{D}_{2}$ in the equivalent circuit, respectively. The grain boundary region exhibits an additional series resistance since the resistivity in the vicinity of grain boundaries is higher than that within the crystallites. ${ }^{17}$ This is accounted for by $R_{\mathrm{s} 2}$, which is connected to $\mathrm{D}_{2}$ in figure 5. A shunt resistance $R_{\text {sh }}$ is connected in parallel to both diodes $\mathrm{D}_{1}$ and $\mathrm{D}_{2}$. Furthermore, a series resistance $R_{\mathrm{S}}$ is connected to all three branches. The equations describing current transport through the cell contain variable diode ideality factors, so that there are no restrictions of current transport mechanisms.

In accordance with this equivalent circuit, the total current that flows through the cell can be written as follows:

$$
j(V)=j_{1}(V)+j_{2}(V)+\frac{\left(V-j(V) R_{\mathrm{s}}\right)}{R_{\mathrm{sh}}}+j_{\mathrm{ph}} .
$$

Here $R_{\mathrm{S}}$ is the series resistance, $R_{\mathrm{sh}}$ the shunt resistance and $j_{\text {ph }}$ the photo-current. The quantities $j_{1}(V)$ and $j_{2}(V)$

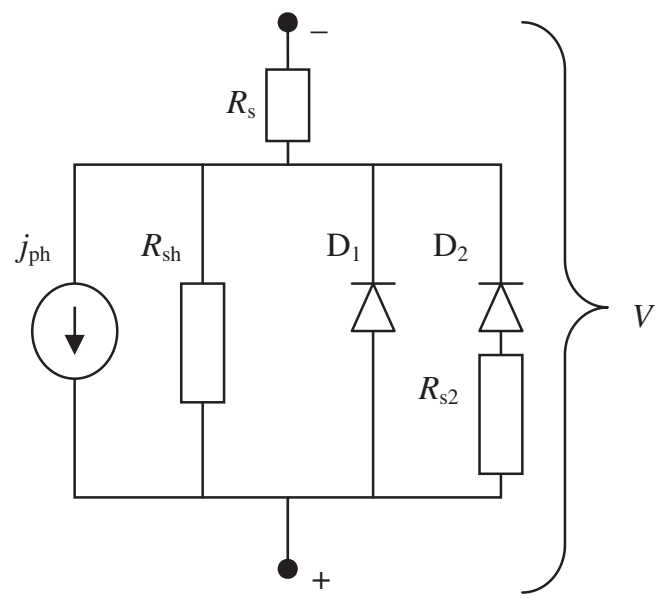

Figure 5. Modified two-diode equivalent circuit used in this study for analysing the multi-crystalline silicon solar cell. 
Table 2. Cell fitting parameters before etching.

\begin{tabular}{|c|c|c|c|c|c|c|c|}
\hline$I_{\text {ill }}\left(\mathrm{mW} \mathrm{cm}^{-2}\right)$ & $I_{\mathrm{ph}}\left(\mathrm{mA} \mathrm{cm}^{-2}\right)$ & $n_{1}$ & $n_{2}$ & $j_{01}\left(\mathrm{~A} \mathrm{~cm}^{-2}\right)$ & $j_{02}\left(\mathrm{~A} \mathrm{~cm}^{-2}\right)$ & $R_{\mathrm{S}}\left(\Omega \mathrm{cm}^{2}\right)$ & $R_{\mathrm{s} 2}\left(\Omega \mathrm{cm}^{2}\right)$ \\
\hline 5.55 & 0.16 & 1.03 & 2.82 & $6.38 \times 10^{-12}$ & $3.14 \times 10^{-6}$ & 0.32 & $4.10 \times 10^{-4}$ \\
\hline 7.4 & 0.37 & 1.02 & 3.00 & $6.38 \times 10^{-12}$ & $4.18 \times 10^{-6}$ & 0.37 & $4.10 \times 10^{-4}$ \\
\hline 9.27 & 0.76 & 1.02 & 2.99 & $4.24 \times 10^{-12}$ & $4.39 \times 10^{-6}$ & 0.32 & $4.10 \times 10^{-4}$ \\
\hline 11.12 & 1.35 & 1.02 & 2.99 & $4.24 \times 10^{-12}$ & $4.39 \times 10^{-6}$ & 0.32 & $4.10 \times 10^{-4}$ \\
\hline 13.97 & 2.16 & 1.02 & 2.99 & $4.25 \times 10^{-12}$ & $4.63 \times 10^{-6}$ & 0.32 & $8.97 \times 10^{-5}$ \\
\hline 14.82 & 3.19 & 1.02 & 2.99 & $4.25 \times 10^{-12}$ & $4.63 \times 10^{-6}$ & 0.32 & $8.97 \times 10^{-5}$ \\
\hline 16.67 & 4.50 & 1.01 & 2.99 & $4.42 \times 10^{-12}$ & $4.81 \times 10^{-6}$ & 0.30 & $6.20 \times 10^{-5}$ \\
\hline 19.33 & 5.85 & 1.01 & 2.99 & $4.42 \times 10^{-12}$ & $4.81 \times 10^{-6}$ & 0.30 & $6.20 \times 10^{-5}$ \\
\hline 22.33 & 7.55 & 1.02 & 2.96 & $5.06 \times 10^{-12}$ & $4.93 \times 10^{-6}$ & 0.30 & $6.20 \times 10^{-5}$ \\
\hline 25.67 & 9.40 & 1.02 & 2.96 & $5.21 \times 10^{-12}$ & $4.93 \times 10^{-6}$ & 0.32 & $6.20 \times 10^{-5}$ \\
\hline 29 & 9.97 & 1.02 & 2.96 & $5.08 \times 10^{-12}$ & $4.93 \times 10^{-6}$ & 0.34 & $6.20 \times 10^{-5}$ \\
\hline 32.33 & 12.10 & 1.03 & 2.96 & $7.87 \times 10^{-12}$ & $4.93 \times 10^{-6}$ & 0.34 & $6.20 \times 10^{-5}$ \\
\hline
\end{tabular}

Table 3. Cell fitting parameters after etching.

\begin{tabular}{|c|c|c|c|c|c|c|c|}
\hline$I_{\text {ill }}\left(\mathrm{mW} \mathrm{cm}^{-2}\right)$ & $I_{\mathrm{ph}}\left(\mathrm{mA} \mathrm{cm}^{-2}\right)$ & $n_{1}$ & $n_{2}$ & $j_{01}\left(\mathrm{~A} \mathrm{~cm}^{-2}\right)$ & $j_{02}\left(\mathrm{~A} \mathrm{~cm}^{-2}\right)$ & $R_{\mathrm{S}}\left(\Omega \mathrm{cm}^{2}\right)$ & $R_{\mathrm{s} 2}\left(\Omega \mathrm{cm}^{2}\right)$ \\
\hline 5.55 & 0.13 & 0.94 & 2.79 & $1.75 \times 10^{-13}$ & $3.33 \times 10^{-6}$ & 0.13 & 0.02 \\
\hline 7.4 & 0.40 & 0.94 & 2.79 & $1.75 \times 10^{-13}$ & $3.33 \times 10^{-6}$ & 0.13 & 0.02 \\
\hline 9.27 & 0.87 & 0.94 & 2.79 & $1.75 \times 10^{-13}$ & $3.33 \times 10^{-6}$ & 0.13 & 0.02 \\
\hline 11.12 & 1.52 & 0.94 & 2.74 & $1.75 \times 10^{-13}$ & $3.00 \times 10^{-6}$ & 0.13 & 0.02 \\
\hline 13.97 & 2.39 & 0.94 & 2.74 & $1.75 \times 10^{-13}$ & $3.17 \times 10^{-6}$ & 0.13 & 0.02 \\
\hline 14.82 & 3.54 & 0.94 & 2.74 & $1.75 \times 10^{-13}$ & $3.62 \times 10^{-6}$ & 0.13 & 0.88 \\
\hline 16.67 & 4.86 & 0.94 & 2.74 & $1.75 \times 10^{-13}$ & $3.92 \times 10^{-6}$ & 0.13 & 0.90 \\
\hline 19.33 & 6.43 & 0.94 & 2.74 & $1.75 \times 10^{-13}$ & $4.38 \times 10^{-6}$ & 0.13 & 0.91 \\
\hline 22.33 & 8.30 & 0.94 & 2.74 & $1.75 \times 10^{-13}$ & $4.83 \times 10^{-6}$ & 0.13 & 0.92 \\
\hline 25.67 & 10.35 & 0.94 & 2.74 & $2.31 \times 10^{-13}$ & $7.00 \times 10^{-6}$ & 0.13 & 2.95 \\
\hline 29 & 12.60 & 0.94 & 2.74 & $2.90 \times 10^{-13}$ & $8.76 \times 10^{-6}$ & 0.14 & 3.52 \\
\hline 32.33 & 15.20 & 0.94 & 2.74 & $3.01 \times 10^{-13}$ & $1.10 \times 10^{-5}$ & 0.13 & 3.73 \\
\hline
\end{tabular}

represent currents that flow through diode $\mathrm{D}_{1}$ and diode $\mathrm{D}_{2}$, respectively, and can be written as

$$
\begin{aligned}
& j_{1}(V)=j_{01}\left\{\exp \left[\frac{q\left(V-j(V) R_{\mathrm{s}}\right)}{n_{1} k T}\right]-1\right\}, \\
& j_{2}(V)=j_{02}\left\{\exp \left[\frac{q\left(V-j(V) R_{\mathrm{s}}-j_{2}(V) R_{\mathrm{s} 2}\right)}{n_{2} k T}\right]-1\right\},
\end{aligned}
$$

where $j_{01}$ and $j_{02}$ are the saturation current densities, $n_{1}$ and $n_{2}$ the diode ideality factors, $q$ the electron charge, $k$ the Boltzmann constant, $T$ the absolute temperature and $R_{\mathrm{s} 2}$ an additional series resistance connected to $\mathrm{D}_{2}$.

The analysis of current-voltage characteristics revealed that the shunt resistance is very high so that its effect on all characteristics can be neglected. The fitting method used was a least-squares method. The obtained diode parameters are presented in tables 2 and 3, and illustrated in figure 6 for the cell before and after etching.

The value of the diode ideality factor $n_{1}$ of the first diode $\mathrm{D}_{1}$ is close to 1 for both diodes before and after etching, this indicates that current transport in the first diode is dominated by recombination in the depletion layer, allocated to a recombination in the crystalline region. ${ }^{17}$ As illustrated in figure 6 the changes in $n_{1}$ due to etching can be neglected. This means that etching does not significantly affect recombination in the crystalline region. The diode ideality factor $n_{2}$ of the second diode $\mathrm{D}_{2}$ is greater than 2 , which indicates that current transport in the second diode is dominated by recombination at grain boundaries. The values of $n_{2}$ are reduced after etching indicating reduced grain boundary recombination. The saturation current density values $j_{01}$ of $\mathrm{D}_{1}$ are reduced by approximately two orders of magnitude after etching, whereas the corresponding values of $\mathrm{D}_{2}$ are lower at low illumination intensity values and higher at high illumination intensity values after etching. The series resistance $R_{\mathrm{s}}$ slightly decreases after etching. The reduction of $n_{1}, j_{01}$ and $R_{\mathrm{s}}$ in $\mathrm{D}_{1}$ after etching represents an advantage in diode behaviour, whereas the disadvantage of etching seems to appear in the increase of $j_{02}$ and $R_{\mathrm{s} 2}$ in $\mathrm{D}_{2}$. At illumination intensity values up to $I_{\text {ill }} \approx 13 \mathrm{~mW} \mathrm{~cm}^{-2} R_{\mathrm{s} 2}$ increases slightly after etching, with increasing illumination intensity values higher than that value $R_{\mathrm{s} 2}$ increases by approximately two orders of magnitude. In order to explain this behaviour we assume that etching destroys the surface of mc-Si cell forming porous silicon. 

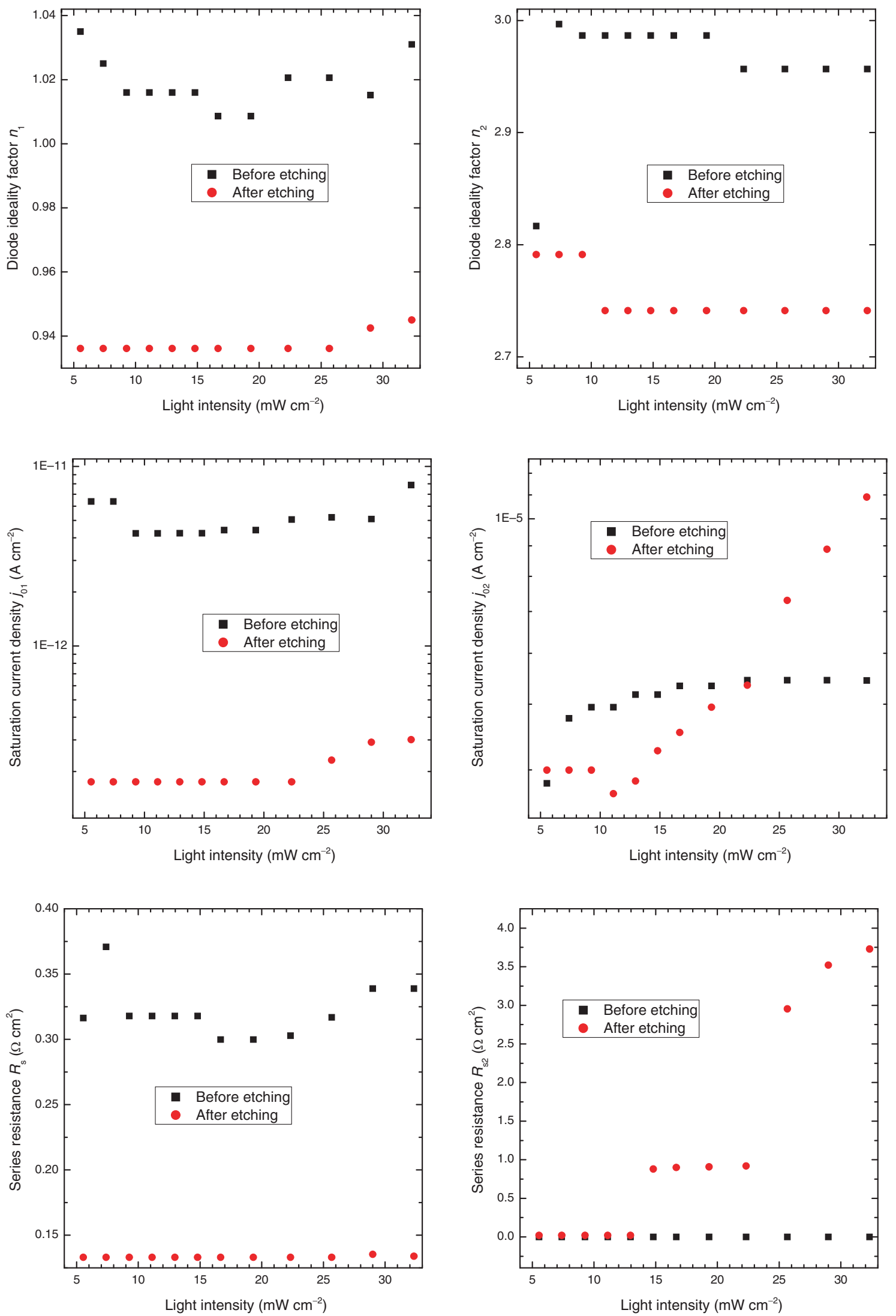

Figure 6. Parameters describing the cells before and after etching. 
This porous layer is high resistive and it is difficult to determine its exact value. ${ }^{18,19}$ This leads to a high series resistance $R_{\mathrm{s} 2}$. This resistance leads to considerably high losses in solar cell fill factor, as it will be demonstrated below.

In order to demonstrate the effect of $R_{\mathrm{s} 2}$ on the cell characteristics the contribution of each of the two diodes $\left(D_{1}\right.$ and $D_{2}$ ) to the measured characteristic is presented in figure 7 for the measured characteristics at an illumination intensity of $I_{\text {ill }} \approx 22 \mathrm{~mW} \mathrm{~cm}^{-2}$ before and after etching. In this figure, calculated $j_{1}$ and $j_{2}$ using equations (3) and (4) and the data
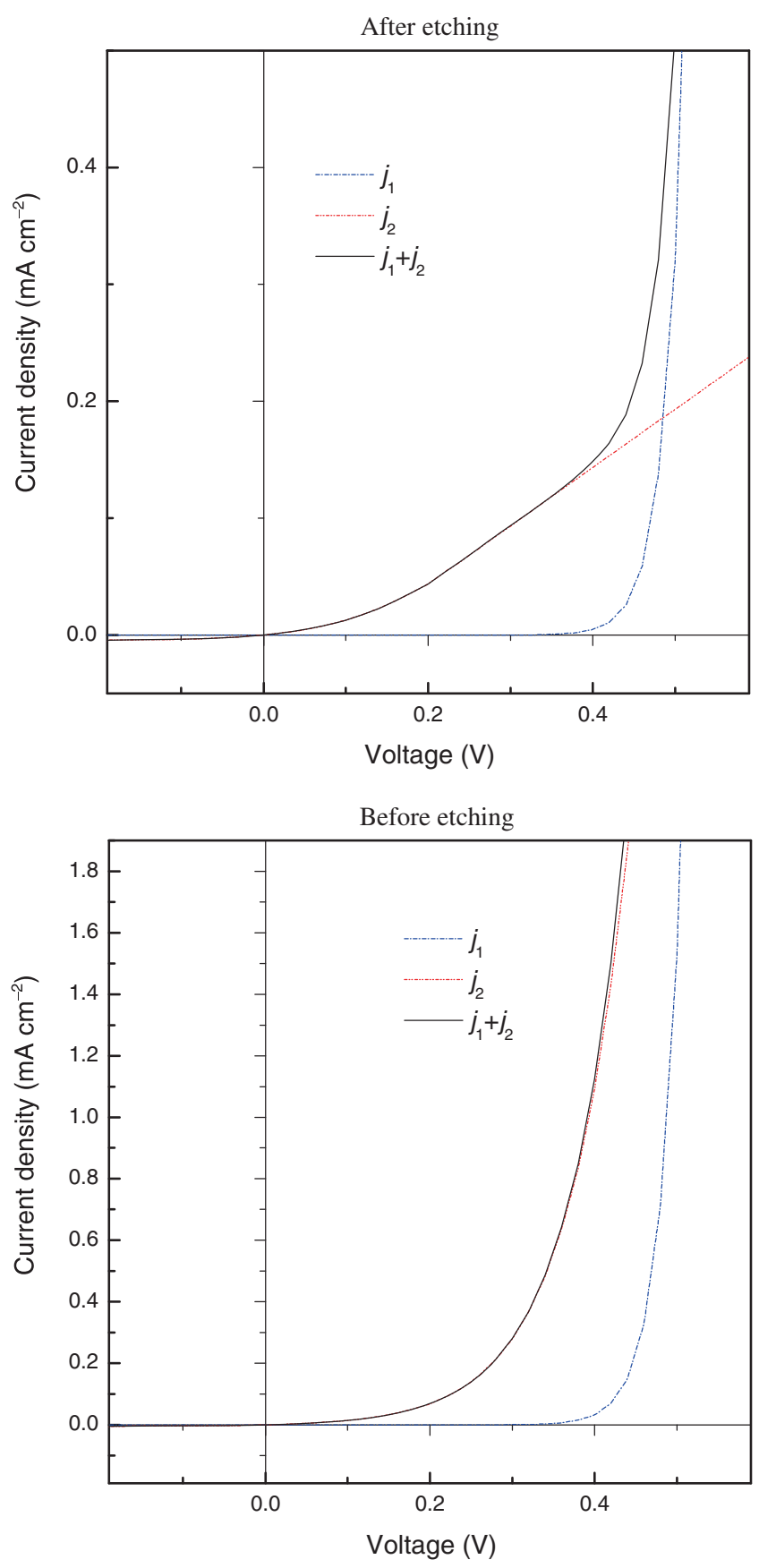

Figure 7. Calculated contributions of $\mathrm{D}_{1}$ and $\mathrm{D}_{2}$ to the measured characteristic at an illumination intensity of $I_{\text {ill }}=22 \mathrm{~mW} \mathrm{~cm}^{-2}$ before and after etching. presented in tables 2 and 3 are plotted $v s$. $V$ together with their sum $j_{1}+j_{2}$.

Figure 7 clearly demonstrates the immense effect of $R_{\mathrm{s} 2}$ on the cell characteristics after etching, especially in the range of $0-0.4 \mathrm{~V}$. This range is usually used to determine cell fill factor. Before etching the values of $R_{\mathrm{s} 2}$ are not so high to considerably affect the cell characteristics and cell fill factor.

\section{Conclusion}

Porous silicon formation on the top of mc-Si solar cells layer has an advantage that it reduces photocurrent losses due to reduced reflection at its surface, and therefore it enhances short-circuit current density and open-circuit voltage values. However, it has a disadvantage that it is high resistive and therefore it leads to considerably high losses in solar cell fill factor. Investigation in fill factor improvement through reducing porous silicon resistivity might be an important goal.

\section{References}

1. Pavesi L and Dubos P 1997 Semicond. Sci. Technol. 12570

2. Dimitrov D B 1995 Phys. Rev. B 511562

3. Tsamis C, Tsoura L, Nassiopoulou A G, Travlos A, Salmas C E, Hatzilyberis K A and Androutsopoulos G P 2002 IEEE Sens. J. 289

4. Archer M and Fauchet P M 2003 Phys. Status Solidi A 198503

5. Barillaro G, Nannini A and Pieri F 2003 Sens. Actuators B 93 263

6. Bastide S, Albu-Yaron A, Strehlke S and Lévy-Clément C 1999 Sol. Energy Mater. Sol. Cells 57393

7. Dubey R S and Gautam D K 2011 Superlattices Microstruct. 50269

8. Dzhafarov T D, Aslanov S S, Ragimov S H, Sadigov M S and Aydin Yuksel S 2012 Vacuum 861875

9. Lee M, Wang Y and Chu C 1999 Sol. Energy Mater. Sol. Cells 5959

10. Strehlke S, Sarti D, Krotkus A, Grigiras K and Lévy-Clément C 1997 Thin Solid Films 297291

11. Nussbaumer H, Willeke G and Bucher E 1994 J. Appl. Phys. 752202

12. Menna P, Di Francia G and La Ferrara V 1995 Sol. Energy Mater. Sol. Cells 3713

13. Bilyalov R, Stalmans L, Schirone L and Lévy-Clément C 1999 IEEE Trans. Electron. Dev. 462035

14. Naddaf M, Awad F and Soukeih M 2007 Mater. Sci. Eng. C 27 832

15. Hou X, Fan H, Lei X, Zhang F, Li M, Ming-Ren Y and Wang X 1996 Appl. Phys. Lett. 682323

16. Kassis A and Saad M 2010 Sol. Energy Mater. Sol. Cells 94 2108

17. Lee S E, Lim D G and Yi J 2000 J. Korean Phys. Soc. 3764

18. Ben-Chroin M 1997 Resistivity of porous silicon In: L Canham (ed) Properties of porous silicon (London: INSPEC) p 38-43 and 165-175

19. Parkhutik V 1999 Solid-State Electron. 431121 